\title{
The state of neurosurgical training and education in East Asia: analysis and strategy development for this frontier of the world
}

\author{
Kevin Paul Ferraris, MD, MBA, ${ }^{1}$ Hideaki Matsumura, MD, ${ }^{2}$ Dewa Putu Wisnu Wardhana, MD, ${ }^{3}$ \\ Theodor Vesagas, MD, ${ }^{4}$ Kenny Seng, MD, ${ }^{1,5}$ Mohd Raffiz Mohd Ali, MBChB, ${ }^{6}$ \\ Eiichi Ishikawa, MD, PhD, ${ }^{2}$ Akira Matsumura, MD, PhD, ${ }^{2}$ Rohadi Muhammad Rosyidi, MD, ${ }^{7}$ \\ Tjokorda Mahadewa, MD, PhD, ${ }^{8}$ and Meng-Fai Kuo, MD, EMBA, PhD ${ }^{9}$
}

${ }^{1}$ Section of Neurosurgery, Department of Surgery, Jose R. Reyes Memorial Medical Center, Manila, Philippines; ${ }^{2}$ Department of Neurosurgery, Faculty of Medicine, University of Tsukuba, Ibaraki, Japan; ${ }^{3}$ Division of Neurosurgery, Department of Surgery, Udayana University Hospital, Faculty of Medicine, Udayana University, Bali, Indonesia; ${ }^{4}$ Philippine Board of Neurological Surgery and Philippine Gamma Knife Center, Cardinal Santos Medical Center, Manila, Philippines; ${ }^{5}$ Section of Neurosurgery, Department of Neurosciences, University of the Philippines-Philippine General Hospital, University of the Philippines College of Medicine, Manila, Philippines; ${ }^{6}$ Department of Neurosurgery, Hospital Kuala Lumpur, Malaysia; ${ }^{7}$ Department of Neurosurgery, West

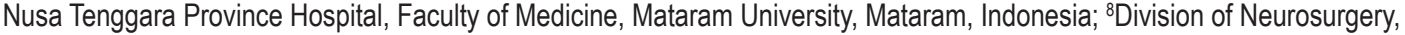
Department of Surgery, Sanglah General Hospital, Faculty of Medicine, Udayana University, Bali, Indonesia; and ${ }^{2}$ Division of Neurosurgery, Department of Surgery, National Taiwan University Hospital, National Taiwan University College of Medicine, Taipei, Taiwan

OBJECTIVE The authors, who are from Indonesia, Japan, Malaysia, the Philippines, and Taiwan, sought to illustrate the processes of training neurosurgeons in their respective settings by presenting data and analyses of the current state of neurosurgical education across the East Asian region.

METHODS The authors obtained quantitative data as key indicators of the neurosurgical workforce from each country. Qualitative data analysis was also done to provide a description of the current state of neurosurgical training and education in the region. A strengths, weaknesses, opportunities, and threats (SWOT) analysis was also done to identify strategies for improvement.

RESULTS The number of neurosurgeons in each country is as follows: 370 in Indonesia, 10,014 in Japan, 152 in Malaysia, 134 in the Philippines, and 639 in Taiwan. With a large neurosurgical workforce, the high-income countries Japan and Taiwan have relatively high neurosurgeon to population ratios of 1 per 13,000 and 1 per 37,000, respectively. In contrast, the low- to middle-income countries Indonesia, Malaysia, and the Philippines have low neurosurgeon to population ratios of 1 per $731,000,1$ per 210,000, and 1 per 807,000 , respectively. In terms of the number of training centers, Japan has 857, Taiwan 30, Indonesia 7, Malaysia 5, and the Philippines 10. In terms of the number of neurosurgical residents, Japan has 1000, Taiwan 170, Indonesia 199, Malaysia 53, and the Philippines 51 . The average number of yearly additions to the neurosurgical workforce is as follows: Japan 180, Taiwan 27, Indonesia 10, Malaysia 4, and the Philippines 3. The different countries included in this report have many similarities and differences in their models and systems of neurosurgical education. Certain important strategies have been formulated in order for the system to be responsive to the needs of the catchment population: 1) establishment of a robust network of international collaboration for reciprocal certification, skills sharing, and subspecialty training; 2) incorporation of in-service residency and fellowship training within the framework of improving access to neurosurgical care; and 3) strengthening health systems, increasing funding, and developing related policies for infrastructure development.

CONCLUSIONS The varied situations of neurosurgical education in the East Asian region require strategies that take into account the different contexts in which programs are structured. Improving the education of current and future neu-

ABBREVIATIONS HIC = high-income country; JNS = Japan Neurosurgical Society; LMIC = low- to middle-income country; SWOT = strengths, weaknesses, opportunities, and threats. SUBMITTED October 31, 2019. ACCEPTED December 19, 2019. INCLUDE WHEN CITING DOI: 10.3171/2019.12.FOCUS19814. 


\begin{abstract}
rosurgeons becomes an important consideration in addressing the health inequalities in terms of access and quality of care afflicting the growing population in this region of the world.

https://thejns.org/doi/abs/10.3171/2019.12.FOCUS19814
\end{abstract}

KEYWORDS Asia; neurosurgical education; neurosurgery certification; global neurosurgery; high-income countries; low- and middle-income countries

$\mathrm{E}$ AST Asia is principally characterized by demographic differences and economic disparities. Neurosurgeons, as human resources for health, ought to be responsive to the demands of their catchment population. The education of current and future neurosurgeons in this region of the world therefore becomes an important consideration because the effective and sustainable training of neurosurgeons increases access to neurosurgical care. ${ }^{28,32}$ In this report, the authors, who are from Indonesia, Japan, Malaysia, the Philippines, and Taiwan, present numerical key indicators of the neurosurgical workforce in their respective settings, describe the current state of neurosurgical education of each country, and offer analysis and potential solutions for improvement.

\section{Methods}

The authors conducted a survey according to a mixedmethods methodology. Qualitative and quantitative data from each of the participating countries were obtained to provide a description of the current state of neurosurgical education in the region.

\section{Numerical Key Indicators}

The authors obtained the current number of neurosurgeons per country from the respective neurosurgical societies and certifying boards. Additionally, the current numbers of training centers and neurosurgical residents, including the average number of yearly additions to the neurosurgical workforce, were obtained. In order to illustrate the impact of the economic infrastructure on the delivery of specialized care, the income category of each country was identified. ${ }^{59}$ Using uniform data on country populations for the year $2019,{ }^{54}$ the neurosurgeon to population ratios per country were also calculated-this ratio being one of the health workforce metrics recommended by the World Health Organization. ${ }^{60}$

\section{Qualitative Data Analysis}

A purposive sample of senior consultant trainers per country was surveyed. On the basis of standard curriculum guidelines per country, as well as their perception of several models of learning that are relevant to neurosurgical education, ${ }^{24}$ these consultants were asked to describe the neurosurgical training environment and educational curricula in their country. The free-text responses that they provided were analyzed and summarized in accordance with qualitative content analysis techniques. ${ }^{49}$

\section{Strengths, Weaknesses, Opportunities, and Threats Analysis}

Strengths, weaknesses, opportunities, and threats (SWOT) analysis - a managerial analysis tool and one of the most widely used tools for strategic planning ${ }^{17}$-is gaining acceptance as an aid in clinical decision-making ${ }^{55}$ and analysis of complicated systems. ${ }^{21}$ Inputs and outputs of the system of neurosurgical education of each country in this report were identified as either strengths or weaknesses, while broader socioeconomic issues, current international policies, and global trends affecting all countries were identified as either opportunities or threats. From this perspective, the SWOT analysis was done to develop potential strategies meant to improve collaborative development of international neurosurgical education in this region of the world.

\section{Results}

Important numerical data (numbers of neurosurgeons, neurosurgeon to population ratios, numbers of training centers, numbers of residents, and average number of yearly additions to the neurosurgical workforce) are summarized in Table 1. With large neurosurgical workforces, the high-income countries (HICs) Japan and Taiwan have relatively high neurosurgeon to population ratios compared with the low- to middle-income countries (LMICs) Indonesia, Malaysia, and the Philippines. LMICs in the region have fewer training centers and residents, and a lower average number of yearly additions to the workforce.

The education and training system of each country is described below.

\section{Indonesia}

Having the lowest neurosurgeon to population ratio (see Table 1), Indonesia has the added problem of maldistribution of neurosurgical care facilities. The practice of neurosurgery is limited by the licensing system and classification of hospitals-each neurosurgeon is allowed to practice at a maximum of 3 hospitals. While the majority of neurosurgeons are practicing in larger medical centers, 198 (23.6\% of neurosurgeon placement) work in less-equipped hospitals, which are generally considered less capable of providing the whole range of adequate neurosurgical care.

The residency education program in Indonesia takes 5.5 years to complete. During the first 3.5 years, residents undergo the first stage in the form of general surgery basic courses, master programs, and basic neurosurgery. Residents may start off assisting in surgery and, as they progress, begin to perform on their own according to the type of case and difficulty index. The 4 levels of neurosurgical competency, based on a modification of the Miller pyramid, ${ }^{24,57}$ provide the foundation of neurosurgical training.

Residents are constantly evaluated while performing their skills under supervision. The Collegium of Indonesian Neurosurgery (COIN) determines the least number of actions and types of cases that must be met by residents 
TABLE 1. Summary of numerical key indicators of neurosurgical workforce across the region

\begin{tabular}{|c|c|c|c|c|c|c|}
\hline Country & Classification* & $\begin{array}{c}\text { No. of } \\
\text { Neurosurgeons }\end{array}$ & $\begin{array}{c}\text { Ratio of Neurosurgeons } \\
\text { to Population }\end{array}$ & $\begin{array}{l}\text { No. of Training } \\
\text { Centers }\end{array}$ & $\begin{array}{l}\text { No. of Neurosurgical } \\
\text { Residents }\end{array}$ & $\begin{array}{l}\text { Average No. of Added } \\
\text { Neurosurgeons per Yr }\end{array}$ \\
\hline Indonesia & Lower-middle income & 370 & $1 / 731,000$ & 7 & 199 & 10 \\
\hline Japan & High income & 10,014 & $1 / 13,000$ & 857 & $1000 \dagger$ & 180 \\
\hline Malaysia & Upper-middle income & 152 & $1 / 210,000$ & 5 & 53 & 4 \\
\hline Philippines & Lower-middle income & 134 & $1 / 807,000$ & 10 & 51 & 3 \\
\hline Taiwan & High income & 639 & $1 / 37,000$ & 30 & 170 & 27 \\
\hline
\end{tabular}

* Based on the World Bank country classification. ${ }^{59}$ For the current 2020 fiscal year, calculated using the World Bank Atlas method, countries with a 2018 gross national income (current US\$) per capita of $\leq \$ 1025$ are low income, $\$ 1026-\$ 3995$ are lower-middle income, $\$ 3996-\$ 12,375$ are upper-middle income, and $\geq \$ 12,376$ are high income.

$\dagger$ Approximate number calculated from the number of entrants into training multiplied by 4 years.

at each stage of education before they can be promoted. ${ }^{25}$ Competency assessment at each stage of education is determined by each of the 7 neurosurgery education centers in Indonesia. The final step for residents to obtain national neurosurgical registration is passing the national board examination, which is held 2 times a year. The examination is conducted in 2 parts: an online computer-based test and an objective structured clinical examination administered by senior members of COIN. An estimated 10 new young neurosurgeons pass the national examinations each year. ${ }^{39}$

Historically, expertise in any neurosurgical subspecialty becomes recognized mainly through the surgeon's consistent effort to expand his or her own ability and experience and work on publications relating to his or her subspecialty of interest. Recently, university-based training for formal subspecialties has been offered in only one center since 2015: Airlangga University. It offers training in neurospine, neurovascular, and neurofunctional subspecialties, each taking about 2 years to complete.

\section{Japan}

Of the 10,014 neurosurgeons in Japan, 7933 are board certified. ${ }^{22}$ The average number of neurosurgeons per 100,000 population was 5.5 in each prefecture, ${ }^{52}$ and Japan has the highest proportion of neurosurgeons compared with its neighboring East Asian countries (see Table 1). Owing to the historical background of medical practice in Japan, neurosurgeons handle not only surgery, but also disease prevention, diagnosis, neurointerventions, drug therapy, radiation therapy, subacute- and chronic-phase treatment, and rehabilitation.

After passing a national examination, aspiring neurosurgeons in Japan planning to engage in clinical practice are required to undertake general medical training, such as internal, emergency, and community medicine, for no less than 2 years at a university hospital or a Ministry-designated hospital. Only after completing this 2-year training period does training to become a neurosurgeon begin.

The training system for neurosurgeons, which was established in 1966, is the second oldest training system for board-certified medical specialists in Japan. ${ }^{52}$ The Japan Neurosurgical Society (JNS) is the organization that awards neurosurgical specialty board certification to graduated trainees and has approved 94 training programs and a total of 857 training centers. ${ }^{22,23}$ These programs are strictly determined by the JNS according to the total number and variety of surgeries and the sufficiency of the medical staff and equipment, and must be reapproved every 5 years. The sufficiency of medical care facilities in providing technologies such as CT and MRI is a characteristic of the Japanese healthcare infrastructure. ${ }^{34,35} \mathrm{Neu}-$ rosurgical specialist trainees can pursue standardized care using CT and MRI everywhere in Japan. To deal with the wide range of training contents, each program consists of one base hospital, such as a university hospital, and several other affiliated hospitals, such as emergency hospitals, regional medical care hospitals, pediatric hospitals, and radiotherapy centers. Residents receive training for at least 4 years. In addition to clinical experiences, residents are required to publish at least one peer-reviewed paper as a first author to qualify to take the examination to become a board-certified neurosurgeon, which is held once a year. This examination is composed of written and oral examinations. In 2019, 245 residents took this examination, and the passing rate was $77 \% .^{22}$ Qualifications to continue to practice as a specialist neurosurgeon must be updated every 5 years. Among over 100 Japanese medical societies, the Japanese Medical Specialty Board has approved neurosurgery as one of the 19 basic clinical departments. These departments are an essential part of medicine in Japan. Because neurosurgery is one of the approved basic clinical departments, neurosurgical specialist trainees can start neurosurgery-specific training soon after finishing the medical practitioner training system. Trainees in other surgical specialties like cardiovascular, gastrointestinal, and thoracic surgery that are not counted among the 19 basic clinical departments must first get board certification for surgery before beginning study of their specialty.

Residents need to gain experience in disease management with approval from clinical instructors. The minimum requirements are strictly fixed by the JNS for each type of disease, such as tumor, cerebrovascular disease, trauma, spinal disease, pediatrics, and functional neurosurgery. The minimum requirements of the surgical cases are also strictly fixed. In general, residents play a leading role in the management of perioperative care. Regarding operative procedures, residents receive step-by-step instruction according to their skills. 
There are also 8 related societies that administer original training systems for subspecialties-the Japanese Society on Surgery for Cerebral Stroke, the Japanese Society for Neuroendovascular Therapy, the Japan Society for Neuro-Oncology, the Japanese Congress for Brain Tumor Surgery, the Japan Society of Neurotraumatology, the Japanese Society for Pediatric Neurosurgery, the Neurospinal Society of Japan, and the Japan Society for Stereotactic and Functional Neurosurgery.

\section{Malaysia}

With a low neurosurgeon to population ratio (see Table 1), Malaysia also has the majority of its neurosurgeons centered at larger cities and state hospitals only, rendering accessibility to neurosurgical services less than optimum in certain rural areas. This is certainly true for East Malaysia, the part of Malaysia in Borneo Island. Notable for a population of over 6 million people, this area in particular is currently being served by only 3 public neurosurgical care units.

About $80 \%$ of neurosurgical disease burden is shouldered by the public hospitals. Given this situation, one would expect higher numbers of neurosurgeons in this sector compared to the private sector. On the contrary, of the 124 neurosurgeons registered with the National Specialist Register in Malaysia, only 45 are currently serving the Ministry of Health or the public sector. Only about 53 neurosurgeons are registered to private hospitals, while the rest are based in university hospitals. ${ }^{30}$

Since 2001, Universiti Sains Malaysia has trained and produced 78 local neurosurgeons. To date, Universiti Sains Malaysia remains the only local institution to train and produce neurosurgeons, which it does through its Masters of Neurosurgery program. Progress is being made to include another local university to share the burden and responsibility of training young neurosurgeons in Malaysia. Upon completion of formal neurosurgical training, a minimum of 2 years of clinical practice is required for registration with the National Specialist Register. ${ }^{30}$

After graduating from medical school, an aspiring neurosurgeon in Malaysia is required to complete 2 years as a house officer, and a minimum of 18 months as a medical officer in a neurosurgery department, followed by another 6 months in general surgery, prior to becoming eligible to apply for the Masters of Neurosurgery. The formal neurosurgical training will then take 4 to 7 years. Phase 1 of this training focuses on core knowledge of neurology, neuroanatomy, neuroanesthesiology, neuroradiology, and neuropathology, as well as neurosurgery. Upon completion, the trainees are sent to one of only 5 recognized public hospitals for phase 2 of training, lasting a minimum of 3 years. This phase focuses on clinical management of neurosurgical disorders. Several monthly reviews are held to monitor the trainee's progress, based on the reports of supervising consultants, surgical logbooks, case reports, and dissertation projects. Formal written and clinical examinations are held at the end of phases 1 and 2, after which the degree of Masters of Neurosurgery is awarded to the successful candidate. This is then followed by another 6 months of a gazettement process and a further 18 months before candidates can be registered with the Na- tional Specialist Register. Thereupon, the candidates become eligible members of the Neurosurgical Association of Malaysia (http://nam.org.my).

Upon completion of the Masters of Neurosurgery, there is no further formal training for these young neurosurgeons. However, many neurosurgeons develop their own niche area and gain further experience and training, albeit at their own expense and effort. Throughout the years, with both personal and infrastructural development, a dedicated center for pediatric neurosurgery was established in Malaysia, with many other general neurosurgery centers recognized for their niche areas, such as neurospine and functional neurosurgery.

\section{The Philippines}

With a low neurosurgeon to population ratio as well (see Table 1), the Philippines has many provinces and regions that are underserved. ${ }^{1}$ Most Filipino neurosurgeons practice as private providers. A smaller proportion of them also concurrently practice in public hospitals and medical centers. Residents train in either public or private institutions.

The neurosurgical residency is a 6-year program. Candidates apply to the training programs of their choice after completion of their internships. At present, there are 10 accredited training programs. Training is, at minimum, 72 months (6 years) in duration. The first year is spent in general surgery. The next 5 years involve rotations in the neurology, neuropathology, neuroradiology, neuroscience, and free electives, and research. A total of 48 months is devoted to neurosurgery, marked by progressively increasing responsibility in clinics.

The Philippine Board of Neurological Surgery is the certifying body for neurosurgical training and education in the Philippines. Training programs are free to plan their teaching and learning activities within a regulated instructional matrix submitted by them to the Board. Programs are encouraged to employ learning activities such as, but not limited to, the following: case- and problem-based learning, simulation, laboratory work, and self-directed and hands-on in-service experiential learning (Philippine Board of Neurological Surgery: Curriculum Guide for Residency Training in Neurological Surgery, 2016).

The certifying examinations come in 3 parts: written, oral, and practical. The written examination covers the subspecialty topics of neurosurgery. Passing this examination is a prerequisite to sitting for the oral examination in the form of an objective structured clinical examination during which the candidates will be expected to show that they have acquired the capability to diagnose and prognosticate neurosurgical disorders, perform major neurosurgical procedures, and manage complications. The practical examination involves demonstrating a neurosurgical procedure to the examiners. This examination is usually waived for graduates of training programs accredited by the Board. Research output is a requisite for graduation. There is a requirement to make one oral or poster presentation at a national or international conference, and to publish at least one clinical paper as the primary author in a peer-reviewed medical journal. There are 2 fellowship programs recognized by the Board at this time: one in 


\section{TABLE 2. SWOT analysis}

\begin{tabular}{|c|c|c|}
\hline Influencing Factors & Strengths & Weaknesses \\
\hline $\begin{array}{l}\text { Internal: capabilities related to country/region (W } \\
\quad \rightarrow \text { S) } \\
\text { External: related to recent trends in global neuro- } \\
\quad \text { surgical education }(T \rightarrow 0)\end{array}$ & $\begin{array}{l}\text { 1. Increasing recognition that neurosurgical } \\
\text { interventions \& care are part of essential } \\
\text { medical care }{ }^{31,46,48} \\
\text { 2. Standardized national examinations as } \\
\text { necessary certification before practice }{ }^{14} \\
\text { 3. In-service training with oversight as } \\
\text { contributory to increased access to } \\
\text { neurosurgical care } \text { chi,45 }^{40}\end{array}$ & $\begin{array}{l}\text { 1. Geographic maldistribution of neurosurgical } \\
\text { workforce in LMICs } \\
\text { 2. Increasing gap btwn no. in neurosurgical work- } \\
\text { force \& demand for care }{ }^{37,51} \\
\text { 3. Underrepresentation of region in global neuro- } \\
\text { surgical research }{ }^{26,37,56} \\
\text { 4. Public-private provider dichotomy \& low health } \\
\text { insurance coverage in LMICs } \\
3,19,40,41\end{array}$ \\
\hline
\end{tabular}

\section{Opportunities}

$>\mathrm{S} \rightarrow>0$

1. Increased access to medical literature \& neurosurgical body of knowledge $2,33,36$

2. Quality improvement curricula becoming available \& accessible ${ }^{38}$

3. Subspecialty training as contributory to improved patient outcomes ${ }^{7,9}$

4. Task-sharing, task-shifting, \& comanagement hospitalist services as potential workforce augmentation ${ }^{5,44,45}$

Threats

1. Physician trainee work-hr limits ${ }^{27}$

2. Expectations to increase value of healthcare by decreasing costs \&/or increasing quality of care ${ }^{29}$

3. Provider vol-outcome relationships vs increased access to neurosurgical care ${ }^{8}$

4. Political inconsistencies in administrative \& funding support by governments \& organizations ${ }^{13,19,43}$
1. Establish robust network of international collaboration for reciprocal certification, skill-sharing, \& subspecialty training $2,4,18,42$

2. Incorporate in-service residency \& fellowship training w/in framework of improving access to neurosurgical care $2,10,11,18$

$<\mathrm{W} \rightarrow>0$

\section{Strategies}

1. Explore novel solutions to augment \& complement neurosurgical workforce $e^{5,44,45}$

2. External validation \& sharing of best practices in neurosurgical education ${ }^{6,36,50}$

3. Increase research output especially related to improved access \& cost control37,58,61

4. Quality improvement systems in data gathering ${ }^{38}$

$\mathrm{O}=$ opportunity; $\mathrm{S}=$ strength; $\mathrm{T}=$ threat; $\mathrm{W}=$ weakness; $>=$ maximize $;<=$ minimize.

spine surgery, and the other in Gamma Knife stereotactic radiosurgery.

\section{Taiwan}

With a greater proportion of neurosurgeons for a relatively smaller population (see Table 1), Taiwan has a comparatively large neurosurgical workforce.

After graduating from medical school, the medical practitioner is required to undertake 2 years of postgraduate training before he or she can engage in neurosurgical residency training. After finishing these 2 years, students begin a 6-year training program for neurosurgery. There are 30 medical centers for training neurosurgeons in Taiwan. Twenty of these 30 medical centers are "base" training centers that may affiliate with the remaining 10 to allow trainees to conduct the full range of the neurosurgical training program in terms of numbers of cases. The training programs are regulated by the Taiwan Neurosurgical Society (TNSS). ${ }^{53}$ In addition to neurosurgery, the residents are required to rotate and obtain basic competencies in neurology, neuropathology, and neuroradiology. At least one peer-reviewed research document written by the trainee as first author is required to qualify to take the certifying examination, which is held yearly. This ex- amination consists of written and oral tests. The TNSS holds training courses for 1st- to 6th-year neurosurgical trainees once a year to cover different fields and topics of neurosurgery..$^{53}$

Some medical centers provide fellowships for subspecialty training. Didactics and hands-on cadaveric dissection courses are also commonplace. There are many organizations offering continuing medical education, such as the Taiwan Neurosurgical Spine Society, Taiwan Society for Pediatric Neurosurgery, Taiwan Society for NeuroOncology, Taiwan Society for Neurovascular and Interventional Surgery, Taiwan Society for Stereotactic Functional Neurosurgery and Radiosurgery, Taiwan Society for Skull Base Surgery, Taiwan Pituitary Society, Taiwan Stroke Society, Taiwan Neurotrauma Society, Taiwan Epilepsy Society, Taiwanese Osteoporosis Association, and many others.

\section{Strategy Development}

Based on the identified SWOTs, certain strategies can be employed (see Table 2). Although by no means all-encompassing, these strategies include the following: increasing the number of training centers and neurosurgical trainees, exploring novel workforce augmentation, improving research and quality improvement systems, 
influencing government and organizational policies on health, applying change management and health-reform principles for improving neurosurgical care, strengthening the health system and health policy, and forming robust international collaborations and institutional partnerships within the framework of global neurosurgery.

\section{Discussion}

For the purposes of discussion, we focus on strategies that improve the weaknesses and reinforce the strengths of neurosurgical training and education in East Asia. These strategies are 1) establishment of a robust network of international collaboration for reciprocal certification, skill-sharing, and subspecialty training; 2) incorporation of in-service residency and fellowship training within the framework of improving access to neurosurgical care; and 3) health system strengthening, increased funding, and enhancement of related policies for infrastructure development.

\section{International Collaboration for Reciprocal Certification, Skill-Sharing, and Subspecialty Training}

With the advent of global surgery, it is now increasingly recognized that neurosurgical care is part of essential medical care ${ }^{31,46,48}$ Inequities in service delivery concerning this specialty are no longer an accepted fact but have become a situation that needs rectifying and that requires a process of collaboration within the larger neurosurgical community. ${ }^{37,51}$

The political will for collaboration has come from international governing bodies and multilateral alliances, ${ }^{4}$ but it still has little effect or influence on the reorganization of neurosurgical specialty in the East Asian region. This ideal collaboration envisions a seamless integration of reciprocal licensing and freedom of place of practice for the human health resources of its member countries, including physicians. However, there remain numerous barriers to the application and full implementation of regionwide collaboration for organized neurosurgery. Various other models of international collaboration have also been implemented in other regions and have been reviewed elsewhere; $, 10,12,18,20$ these present opportunities for bilateral exchange of knowledge and skill-sharing at the minimum, and possibly even reciprocal certification and subspecialty training at best. When realized in a manner that is global in perspective but attuned to local needs, those opportunities will benefit neurosurgeons across the region, especially those in LMICs.

\section{In-Service Residency and Fellowship Training for Improving Access to Neurosurgical Care}

In LMICs where neurosurgeon to population ratios are low and where the poor populations are disadvantaged by the fee-for-service payment scheme, ${ }^{19,40,43}$ the in-service residency and fellowship training model contributes to increased access to neurosurgical care. This means that the majority of those who can ill afford to be treated by private providers are provided the necessary neurosurgical care by residents in publicly funded centers who have ample surgical experience to operate as primary surgeons. Therefore, an increase in the number of neurosurgeons, as well as the means of producing such human health resources, would be the initial step in bridging the gaps in terms of availability and access to neurosurgical care and services.

Access to neurosurgical care is defined in terms of not only problems related to financial capacity but also those related to limitations of geography. The geographic maldistribution coupled with the great consultative demand for neurosurgical services are twin problems of the East Asian region. ${ }^{9,11}$ Because of this, underserved provinces in LMICs like the Philippines have resorted to task-sharing as a way to increase access to neurosurgical care. ${ }^{44,45}$ While Japan boasts the best statistics with regard to the ratio of neurosurgeons to patients in the population, it is interesting to note that $28.9 \%$ of Japanese board-certified neurosurgeons consider the number of neurosurgeons in their country to be too low..$^{52}$ This is due to the fact that the care provided by Japanese neurosurgeons covers a broad range of services not limited to surgery, including disease prevention, neurointervention, radiation therapy, subacuteand chronic-phase treatment, and rehabilitation. This situation contrasts with that in LMICs, where the shortage of neurosurgeons in the workforce is worsened by geographic maldistribution, ${ }^{1}$ lack of infrastructure, and poor overall funding, ${ }^{13,19,33,56}$ highlighting the fact that standard neurosurgical care in this context entails the question not only of access but also of quality. Improving the quality of neurosurgical training and education, therefore, augurs well for improvements in the overall access so deserved by the catchment populations served.

\section{Health System Strengthening, Increased Funding, and Related Policy for Infrastructure Development}

While Japan and Taiwan have the adequacy of infrastructure to support the whole gamut of neurosurgical care, ${ }^{34,35}$ Indonesia and the Philippines have mostly underfunded public facilities which nonetheless continue to have the mandate of providing specialized surgical care. ${ }^{3,41}$ This is largely due to limited investments toward public health by the governments of LMICs. Governments, societies, and organizations may have particular system barriers to participation in global collaborations that include, but are not limited to, insufficient administrative support and low political and funding support. ${ }^{13,19}$ It is imperative to convince governments through their health agencies and ministries that the neurosurgical disease burden has societal costs and leads to economic losses, and that investments for infrastructure development are therefore worthwhile. ${ }^{43,45}$ Additionally, many of the leading causes of mortality in the populations of the region are relevant to the neurosurgeon..$^{15,16}$ Regardless of demographic differences, wherein HICs tend to have aging populations while LMICs have greater proportions of youth and children, certain subsets of the population will require neurosurgical care at some point. Should there be a well-functioning governing or regulatory body, particularly in LMICs, adjustments to the "payment control knob"43 may be explored to reform the practice of organized neurosurgery. The feefor-service payment scheme ought to be reexplored and improved upon so that neurosurgeons in LMICs need not be stuck in their basic need for financial incentives and ad- 
equate remuneration. When the health system of a country is able to adequately support its human health resources, it becomes truly responsive to the needs of the sick population.

\section{Conclusions}

There are a number of challenges and opportunities in the East Asian region in terms of educating the current and future neurosurgical workforce. We have used our findings and analyses to identify potential areas for improvement. Suggested strategies ought to be global in perspective but grounded in the different local contexts.

\section{References}

1. Academy of Filipino Neurosurgeons: Members. Geographic distribution of fellows. Academy of Filipino Neurosurgeons. (http://afninc.org/members/) [Accessed January 13, 2020]

2. Almeida JP, Velásquez C, Karekezi C, Marigil M, Hodaie M, Rutka JT, et al: Global neurosurgery: models for international surgical education and collaboration at one university. Neurosurg Focus 45(4):E5, 2018

3. Andayani NLPEP, Marthias T, Putri LP: Public hospital governance in Indonesia, in Huntington D, Hort K (eds): Public Hospital Governance in Asia and the Pacific, Vol 1. Geneva: World Health Organization Western Pacific Regional Publications, 2015, pp 26-63

4. Association of Southeast Asian Nations: ASEAN Mutual Recognition Arrangement on Medical Practitioners. (https://asean.org/?static_post=asean-mutual-recognitionarrangement-on-medical-practitioners-2) [Accessed January 13, 2020]

5. Cheng HQ: Comanagement hospitalist services for neurosurgery. Neurosurg Clin N Am 26:295-300, x-xi, 2015

6. Conforti LN, Yaghmour NA, Hamstra SJ, Holmboe ES, Kennedy B, Liu JJ, et al: The effect and use of milestones in the assessment of neurological surgery residents and residency programs. J Surg Educ 75:147-155, 2018

7. Das P, Guillaume DJ: Improving outcomes with subspecialization and regionalization, in Guillaume DJ, Hunt MA: Quality and Safety in Neurosurgery. San Diego: Elsevier, 2018, pp 226-235

8. Davies JM, Ozpinar A, Lawton MT: Volume-outcome relationships in neurosurgery. Neurosurg Clin N Am 26:207218, viii, 2015

9. Dewan MC, Onen J, Bow H, Ssenyonga P, Howard C, Warf BC: Subspecialty pediatric neurosurgery training: a skillbased training model for neurosurgeons in low-resourced health systems. Neurosurg Focus 45(4):E2, 2018

10. Dewan MC, Rattani A, Baticulon RE, Faruque S, Johnson WD, Dempsey RJ, et al: Operative and consultative proportions of neurosurgical disease worldwide: estimation from the surgeon perspective. J Neurosurg 130:1098-1106, 2018

11. Dewan MC, Rattani A, Fieggen G, Arraez MA, Servadei F, Boop FA, et al: Global neurosurgery: the current capacity and deficit in the provision of essential neurosurgical care. J Neurosurg 130:1055-1064, 2018

12. Fairholm DJ: International education: a third alternative. Neurosurgery 18:111-114, 1986

13. Fallah PN, Bernstein M: Barriers to participation in global surgery academic collaborations, and possible solutions: a qualitative study. J Neurosurg 130:1157-1165, 2019

14. Gasco J, Braun JD, McCutcheon IE, Black PM: Neurosurgery certification in member societies of the World Federation of Neurosurgical Societies: Asia. World Neurosurg 75:325-334, 2011
15. GBD 2015 Healthcare Access and Quality Collaborators: Healthcare Access and Quality Index based on mortality from causes amenable to personal health care in 195 countries and territories, 1990-2015: a novel analysis from the Global Burden of Disease Study 2015. Lancet 390:231-266, 2017

16. GBD 2015 Neurological Disorders Collaborator Group: Global, regional, and national burden of neurological disorders during 1990-2015: a systematic analysis for the Global Burden of Disease Study 2015. Lancet Neurol 16:877-897, 2017

17. Ghazinoory S, Abdi M, Azadegan-Mehr M: SWOT methodology: a state-of-the-art review for the past, a framework for the future. J Bus Econ Manag 12:24-48, 2011

18. Haglund MM, Fuller AT: Global neurosurgery: innovators, strategies, and the way forward. J Neurosurg 131:993-999, 2019

19. Hort K, Maunganidze N: Public hospital governance: emerging issues and key lessons, in Huntington D, Hort K (eds): Public Hospital Governance in Asia and the Pacific, Vol 1. Geneva: World Health Organization Western Pacific Regional Publications, 2015, pp 300-320

20. Ibrahim GM, Cadotte DW, Bernstein M: A framework for the monitoring and evaluation of international surgical initiatives in low- and middle-income countries. PLoS One 10:e0120368, 2015

21. Jackson ES, Joshi A, Erhardt NL: Recent research on team and organizational diversity: SWOT analysis and implications. J Manage 29:801-830, 2003

22. Japan Neurosurgical Society: 16th Annual Report of General Meeting of Members. Osaka, Japan: Japan Neurosurgical Society, 2019 (Japanese) (https://www.jnss.or.jp/jns_web/ html/activity/meeting/pdf/main/78_syainsoukai_1.pdf) [Accessed January 22, 2020]

23. Japan Neurosurgical Society: List of training facilities 2019. Tokyo: Japan Neurosurgical Society, 2019 (Japanese) (http://jns.umin.ac.jp/jns_wp/wp-content/uploads/2019/11/ programlist_2019.xlsx) [Accessed January 22, 2020]

24. Jensen RL, Alzhrani G, Kestle JRW, Brockmeyer DL, Lamb SM, Couldwell WT: Neurosurgeon as educator: a review of principles of adult education and assessment applied to neurosurgery. J Neurosurg 127:949-957, 2017

25. Kolegium Bedah Saraf Indonesia: Standar Nasional Pendidikan Dokter Spesialis Bedah Saraf. Jakarta: KDSI, 2007

26. Langer A, Díaz-Olavarrieta C, Berdichevsky K, Villar J: Why is research from developing countries underrepresented in international health literature, and what can be done about it? Bull World Health Organ 82:802-803, 2004

27. Lau CY: Quality improvement tools and processes. Neurosurg Clin N Am 26:177-187, viii, 2015

28. Liang KE, Bernstein I, Kato Y, Kawase T, Hodaie M: Enhancing neurosurgical education in low- and middle-income countries: current methods and new advances. Neurol Med Chir (Tokyo) 56:709-715, 2016

29. Liu JJ, Raslan AM, Raskin JS: Use of risk model for assessment of surgical complexity and evaluation of procedural competence, in Guillaume DJ, Hunt MA (eds): Quality and Safety in Neurosurgery. San Diego: Elsevier, 2018, pp 270275

30. Malaysian Medical Council: National Specialist Register. (https://nsr.org.my/list1pview.asp?page=1,) [Accessed January 13, 2020]

31. Meara JG, Leather AJM, Hagander L, Alkire BC, Alonso N, Ameh EA, et al: Global Surgery 2030: evidence and solutions for achieving health, welfare, and economic development. Lancet 386:569-624, 2015

32. Mukhopadhyay S, Punchak M, Rattani A, Hung YC, Dahm J, Faruque S: The global neurosurgical workforce: a mixedmethods assessment of density and growth. J Neurosurg 130:1142-1148, 2019 
33. Nicolosi F, Rossini Z, Zaed I, Kolias AG, Fornari M, Servadei F: Neurosurgical digital teaching in low-middle income countries: beyond the frontiers of traditional education. Neurosurg Focus 45(4):E17, 2018

34. Organisation for Economic Co-operation and Development: Computed tomography exams 2018. OECD Data. (https:// data.oecd.org/healthcare/computed-tomography-ct-exams. htm) [Accessed January 13, 2020]

35. Organisation for Economic Co-operation and Development: Magnetic resonance imaging exams 2018. OECD Data. (https://data.oecd.org/healthcare/magnetic-resonanceimaging-mri-exams.htm\#indicator-chart) [Accessed January 13, 2020]

36. Pang P, Raslan AM, Selden NR: Improving performance by improving education, in Guillaume DJ, Hunt MA (eds): Quality and Safety in Neurosurgery. San Diego: Elsevier, 2018, pp 213-222

37. Park KB, Johnson WD, Dempsey RJ: Global neurosurgery: the unmet need. World Neurosurg 88:32-35, 2016

38. Parker SL, McGirt MJ, Asher AL, Selden NR: Quality improvement in neurological surgery graduate medical education. Neurosurg Clin N Am 26:231-238, ix, 2015

39. Perhimpunan Bedah Syaraf Indonesia: College of Neurosurgery. PERSPEBSI.org (http://perspebsi.org/index.php/ public/organisation/kolegium-view/) [Accessed January 22, 2020]

40. Philippine Statistics Authority (PSA), Inner City Fund (ICF): Philippines National Demographic and Health Survey 2017. Quezon City, Philippines, and Rockville, Maryland: PSA and ICF, 2018, pp 189-199

41. Picazo OF: Public hospital governance in the Philippines, in Huntington D, Hort K (eds): Public Hospital Governance in Asia and the Pacific, Vol 1. Geneva: World Health Organization Western Pacific Regional Publications, 2015, pp 186-221

42. Punchak M, Mukhopadhyay S, Sachdev S, Hung YC, Peeters S, Rattani A, et al: Neurosurgical care: availability and access in low- and middle-income countries. World Neurosurg 112:e240-e254, 2018

43. Roberts MJ, Hsiao W, Berman P, Reich MR: Getting Health Reform Right: A Guide to Improving Performance and Equity. New York: Oxford University Press, 2004, p 190_ 195,219

44. Robertson FC, Briones R, Mekary RA, Baticulon RE, Jimenez MA, Leather AJM, et al: Task-sharing for emergency neurosurgery: a retrospective cohort study in the Philippines. World Neurosurg X [epub ahead of print], 2019

45. Robertson FC, Esene IN, Kolias AG, Kamalo P, Fieggen G, Gormley WB, et al: Task-shifting and task-sharing in neurosurgery: an international survey of current practices in lowand middle-income countries. World Neurosurg $\mathbf{X}$ [epub ahead of print], 2019

46. Rosseau G, Johnson WD, Park KB, Arráez Sánchez M, Servadei F, Vaughan KA: Global neurosurgery: current and potential impact of neurosurgeons at the World Health Organization and the World Health Assembly. Executive summary of the World Federation of Neurosurgical Societies-World Health Organization Liaison Committee at the 71st World Health Assembly. Neurosurg Focus 45(4):E18, 2018

47. Rudolfson N, Dewan MC, Park KB, Shrime MG, Meara JG, Alkire BC: The economic consequences of neurosurgical disease in low- and middle-income countries. J Neurosurg 130:1149-1156, 2018

48. Rutka JT: Editorial. Global neurosurgery and our social responsibility. J Neurosurg 130:1050-1052, 2019

49. Sandelowski M: Whatever happened to qualitative description? Res Nurs Health 23:334-340, 2000
50. Selden NR, Abosch A, Byrne RW, Harbaugh RE, Krauss WE, Mapstone TB, et al: Neurological surgery milestones. J Grad Med Educ 5 (1 Suppl 1):24-35, 2013

51. Servadei F, Rossini Z, Nicolosi F, Morselli C, Park KB: The role of neurosurgery in countries with limited facilities: facts and challenges. World Neurosurg 112:315-321, 2018

52. Suzuki M, Suehiro E: [Questionnaire survey for board-certified neurosurgeons.] Jpn J Neurosurg (Tokyo) 26:817-828, 2017 (Japanese)

53. Taiwan Neurosurgical Society: Board certification. (Taiwanese) (https://www.neurosurgery.org.tw/?page_id=26) [Accessed January 22, 2020]

54. United Nations: World Population Prospects 2019, Online Edition. (https://population.un.org/wpp/Download/Standard/ Population/) [Accessed January 13, 2020] (Japanese)

55. von Kodolitsch Y, Bernhardt AM, Robinson PN, Kölbel T, Reichenspurner H, Debus S, et al: Analysis of strengths, weaknesses, opportunities, and threats as a tool for translating evidence into individualized medical strategies (ISWOT). Aorta (Stamford) 3:98-107, 2015

56. Wahjoepramono EJ: Editorial: Neurosurgery in Indonesia. Int Neurosci J 1:e863, 2015

57. Williams BW, Byrne PD, Welindt D, Williams MV: Miller's pyramid and core competency assessment: a study in relationship construct validity. J Contin Educ Health Prof 36:295-299, 2016

58. Witiw CD, Nathan V, Bernstein M: Economics, innovation, and quality improvement in neurosurgery. Neurosurg Clin $\mathbf{N}$ Am 26:197-205, viii, 2015

59. World Bank Group: World Bank Country Lending Groups Country Classification. (https://datahelpdesk.worldbank. org/knowledgebase/articles/906519-world-bank-country-andlending-groups) [Accessed January 13, 2020]

60. World Health Organization: Human Resources for Health: Toolkit on Monitoring Health Systems Strengthening. (https://www.who.int/healthinfo/statistics/toolkit_hss/EN_ PDF_Toolkit_HSS_HumanResources_oct08.pdf) [Accessed January 13, 2020]

61. Zygourakis CC, Kahn JG: Cost-effectiveness research in neurosurgery. Neurosurg Clin N Am 26:189-196, viii, 2015

\section{Disclosures}

The authors report no conflict of interest concerning the materials or methods used in this study or the findings specified in this paper.

\section{Author Contributions}

Conception and design: Ferraris, H Matsumura, Wardhana, Kuo. Acquisition of data: Ferraris, H Matsumura, Wardhana, Vesagas, Mohd Ali, Kuo. Analysis and interpretation of data: Ferraris, H Matsumura, Wardhana, Vesagas, Seng, Ishikawa, A Matsumura, Rosyidi, Mahadewa. Drafting the article: Ferraris, H Matsumura, Wardhana, Vesagas, Mohd Ali, Kuo. Critically revising the article: Ferraris, H Matsumura, Wardhana, Vesagas, Seng, Ishikawa, A Matsumura, Rosyidi, Mahadewa, Kuo. Reviewed submitted version of manuscript: all authors. Approved the final version of the manuscript on behalf of all authors: Ferraris. Administrative/ technical/material support: Ferraris, Vesagas, Seng, Mohd Ali. Study supervision: Vesagas, Seng, Kuo.

\section{Correspondence}

Kevin Paul Ferraris: Jose R. Reyes Memorial Medical Center, Manila, Philippines. kpferraris@gmail.com. 